\title{
The Kornati fire accident - aerodynamic and thermodynamic aspects of the accident
}

\author{
B. Klarin ${ }^{1}$, N. Ninic ${ }^{2}$, D. Stipanicev ${ }^{3}$, S. Nizetic ${ }^{2}$ \& D. Krstinic ${ }^{4}$ \\ ${ }^{1}$ Department of Fluid Mechanics, Faculty of Electrical Engineering, \\ Mechanical Engineering and Naval Architecture, University of Split, \\ Split, Croatia \\ ${ }^{2}$ Department of Thermodynamics, Faculty of Electrical Engineering, \\ Mechanical Engineering and Naval Architecture, University of Split, \\ Split, Croatia \\ ${ }^{3}$ Department for Modelling and Intelligent Systems, \\ Faculty of Electrical Engineering, Mechanical Engineering and Naval \\ Architecture, University of Split, Split, Croatia \\ ${ }^{4}$ Center for Scientific Computing, Faculty of Electrical Engineering, \\ Mechanical Engineering and Naval Architecture, University of Split, \\ Split, Croatia
}

\begin{abstract}
The biggest fire fighting accident in the history of Croatia happened on August 30,2007 . The routine fire fighting operation ended with 12 dead and one badly injured firefighter. That was the biggest human loss in the history of fire fighting in Croatia. In order to understand the Kornati accident, a research team was formed and an independent scientific investigation was performed. The accident was analyzed from meteorological, vegetation, thermodynamic and aerodynamic points of view, and several simulation models were used. This paper describes the Kornati accident from aerodynamic and thermodynamic points of view and gives one possible explanation for the Kornati accident. Based on the actual Kornati accident data and observations of the accident site, qualitative and quantitative analyses have been performed and a few interesting conclusions have been derived.
\end{abstract}

Keywords: open fire, boundary layer, flow obstacles, thermal shock. 


\section{Introduction}

The island of Kornat is the largest of 365 islands in Croatia's Kornati National Park, a popular tourist resort. On Sunday, August 30, 2007, in small canyon over the Sipnata Bay on Kornat, twelve firefighters died of injuries. Firefighters tried to slack fire at the beginning, five hours earlier in Vrulja Bay. Vrulja Bay is settled upwind, $6.6 \mathrm{~km}$ southeast. In addition to the strong S-E wind, several aspects relating to the enclosed location played important roles in the accident, as described in detail in [1] and briefly in [2]. The most important characteristics of the area are:

1. The location has stone terrain with no pathways, and a complex topography: it is a small canyon about $500 \mathrm{~m}$ long, closed from three sides -- east (Veli vrh, 212 $\mathrm{m})$, north (Meja, $150 \mathrm{~m}$ ) and west (Glavica, $135 \mathrm{~m}$ ) -- and open only from the south.

2. The canyon's main axis is directed to the north, with $15 \%\left(9^{\circ}\right)$ average slope, and $29 \%\left(16^{\circ}\right)$ and $45 \%\left(24^{\circ}\right)$ maximum slopes on the left and right sides of canyon, respectively.

3. The total area of the canyon bottom, which was burned, is $99,887 \mathrm{~m}^{2}$ (ca. 10 ha).

4. The location has low and rare vegetation, mostly grass, with $35 \%-45 \%$ woody vegetation and total cover between $45 \%-55 \%$. There are only a few small isolated trees and bushes.

5. The fuel load ranged from $0.561 \mathrm{~kg} / \mathrm{m}^{2}-0.837 \mathrm{~kg} / \mathrm{m}^{2}$, and the average vegetation heat content was estimated to be $18,000 \mathrm{~kJ} / \mathrm{kg}$.

6. Vegetation was extremely flammable, with ignition delay less than $2 \mathrm{~s}$, and the average burning time of grass vegetation was $12 \mathrm{~s}$.

7. The humidity content of the grass vegetation ranged from $12 \%$ to $14 \%$.

8. The strong S-E wind (jugo) was blowing, exceeding $10 \mathrm{~m} / \mathrm{s}(36 \mathrm{~km} / \mathrm{h})$.

9. According to the MM5 model, the possibility of the formation of a surface jet stream with maximum speed at approximately $200 \mathrm{~m}$ above sea level was elevated.

10. Dehydrated leaves on several trees showed the direction of the hot air flow from south to north.

11. Visible layers of burned and dehydrated bark, branches and leaves were present on several trees following the thermal boundary layer composition with heights from $0.5 \mathrm{~m}$ on the south side to $3.0 \mathrm{~m}$ on the north side of the canyon.

12. Glavica hill, settled on the west side, was unburned at the upper part.

13. We visited the accident site twice. The first visit was on September 25 th when the weather conditions were similar to those on the day of the accident.

The basis for our assumptions, investigation and conclusions include the firefighters' path tracking, incidences and reasonable assumptions according to the first official reconstruction of their path one day after the accident, witnesses' evidence, the first interview from an injured fireman, conversations with other firefighters, officials and staff engaged in the same fire, and personal observations during accident site visits. 
In this paper, preliminary results are presented. We would like to emphasise that this was not a police investigation, so we have not considered possible nonnatural accident factors like gasoline, bombs or the like. Our main aim was to determine whether it is possible to explain the cause of the accident only by natural forces using well-known methods of fire propagation simulation and numerical analysis of flow and thermal boundary layer development. This paper gives one possible explanation for how it was possible that a relatively small amount of energy per unit area could result in such a tragedy.

\section{Assumptions based on available evidence and facts}

We make several assumptions, shown in fig. 1:

1. If we use only the common assumptions of fire development, there is not enough energy in a grassy landscape for fire development that would result in this violent accident.

2. Stones on the terrain are large, with high grass in between. No one can walk or run on this terrain, especially not heavily loaded and equipped firefighters. Only short jumps are possible as a means to move around. Natural stone walls up to 5 $\mathrm{m}$ high serve as obstacles; therefore, firefighters must follow the directions of these stone walls.

3. Veli Vrh hill is the main terrain obstacle for air flow above the canyon. Its side line is almost perpendicular to Kornati Island's main axis. It can be expected that the main air flow bypasses the peak. Because of the relative canyon depth, large eddies can be produced over the canyon. This means there is local backward flow.

4. The canyon over Sipnata Bay has its main axis in the north-south direction. The canyon begins at sea level with the main part just below Veli Vrh hill side. The canyon end is on the north side, just below the maximum jet stream layer. On this side is a small plateau located between Veli Vrh and Meja. On the east side of the canyon lies a flat skew plain, which was the location of the accident. The main thermal boundary layer was developed here.

5. The Meja hill was the location of the firefighters' helicopter landing. Their intention was to reach the water reservoir that was previously left by the same helicopter on the south side of Veli Vrh hill.

6. A strong S-E wind was blowing following the Kornat island main axis. It is assumed that the fire first hit the Veli Vrh hill. It was forced by the surface jet stream downward, so it jumped into the canyon aided by backward flow. It is reasonable to assume that when the fire came to the accident location enclosure, hot air flowed up the east canyon side and directly to the firefighters' position.

7. The surface jet stream layer over the complex terrain caused tunnelling of the hot air flow and renders analysis very complex. Therefore, some reasonable assumptions have to be made in order to achieve satisfactory results.

8. There are two factors that aid the analysis. The first is the presence of dehydrated leaves on several trees in the path of the hot air flow. The hot air speed does not allow for burning, but only for heat transfer, which dries up leaves. Few other places in surrounding locations are visible with dry leaves in different paths. 


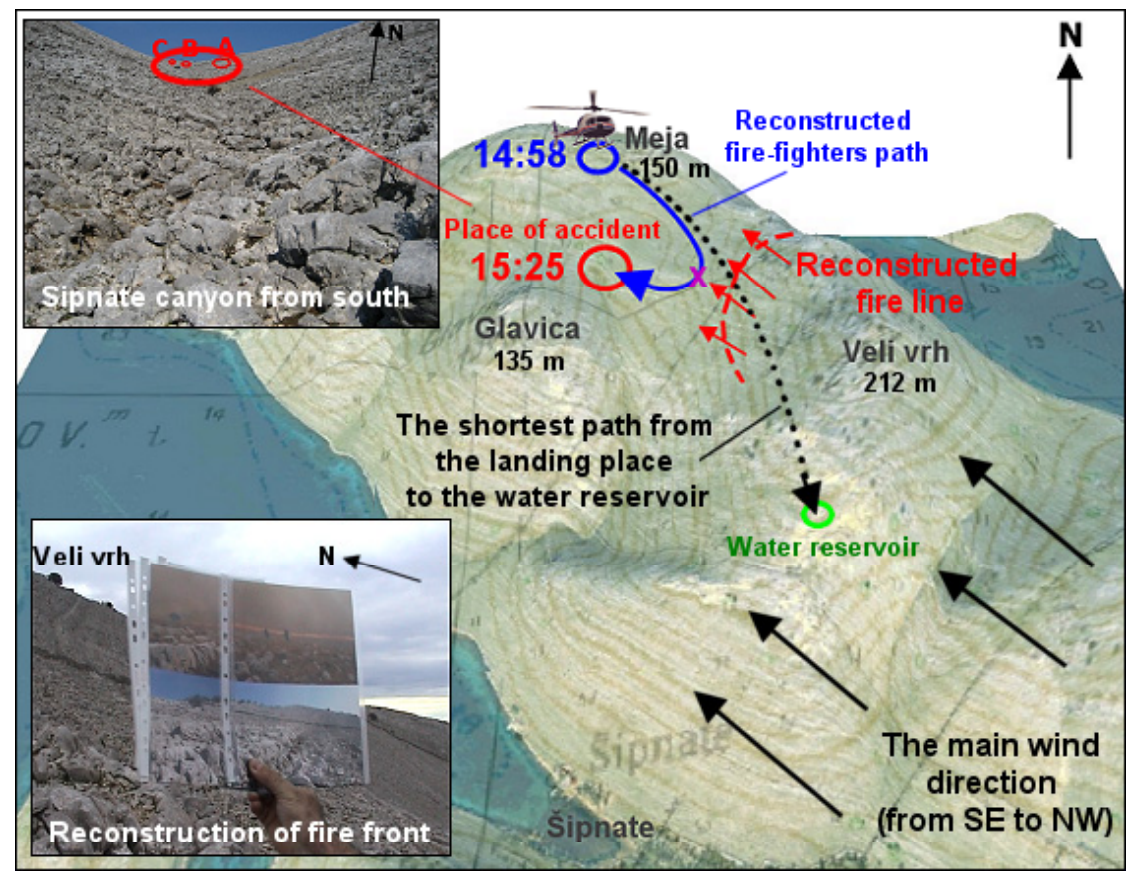

Figure 1: The location of the accident and important facts about the accident, including fire front reconstruction from photos taken by firefighters half an hour before the accident.

9. Another aiding fact is the visible layers on several small trees, composed of burned and dehydrated bark, branches and leaves, following the thermal boundary layer development from the bottom of the canyon $(0.5 \mathrm{~m})$ up to the middle part $(1.7 \mathrm{~m})$ and the plateau at the end $(3.0 \mathrm{~m})$. These heights provide iterative backward analysis of the thermal boundary layer.

10. Half of Glavica hill was unburned due to backward flow caused by a large eddy, and the peak of Veli Vrh was partly unburned, probably due to a strong wind in the surface jet stream.

11. The first canyon section is not visible from the location of the accident.

\section{Fire propagation simulation}

The fire began between 11:00 and 11:30 at Vrulje bay, located $6.6 \mathrm{~km} \mathrm{SE}$ of the Sipnate canyon. The accident happened between 15:20 and 15:30. At the University of Split, we developed a fire propagation model based on Rothermel equations and cellular automata particularly adapted for the Croatian coast and islands. We applied this model to the spread of the Kornat island fire. The biggest problem was to derive an appropriate vegetation map because Croatian vegetation has never been analysed according to fire spread characteristics. Our approach was to use Kornat island vegetation maps and Kornat CORINE 2000 land cover - land use classification and replace their vegetation categories with 
standard fuel models proposed by Albini-Anderson [3] and Scott-Burgan [4]. One of the models is shown in fig. 2. During our research, many simulations were performed to find appropriate input parameters that would best fit the observed data, particularly the fire's time of arrival at the accident location. It is important to emphasise that all simulations show a faster propagation of the fire front on the north side of Kornat island, as shown in fig. 2. Witnesses mention this as well, and this fact was used in the reconstruction of the firefighters' path, shown in fig. 1. Average fire propagation speed between ignition point and location of accident was $0.46 \mathrm{~m} / \mathrm{s}$.

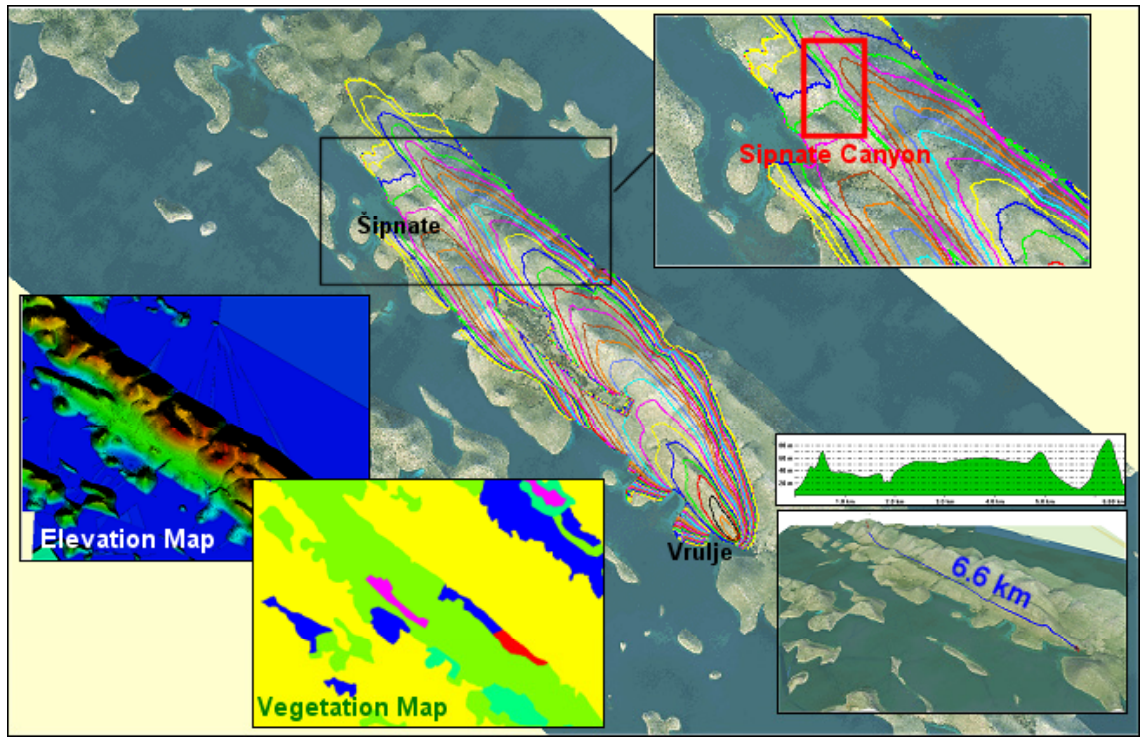

Figure 2: $\quad$ Fire spread simulation from the ignition point at Vrulje bay to the location of accident at Sipnate canyon based on Rothermel equations and adapted for Croatia at the University of Split.

The second part of our analysis was the fire propagation inside the Sipnate canyon. In Sipnate canyon, the dominant vegetation type was very dry grass. Fuel load estimation based on vegetation sampling was estimated to be 0.561 $\mathrm{kg} / \mathrm{m}^{2}-0.837 \mathrm{~kg} / \mathrm{m}^{2}$ [2]. The most similar standard grass vegetation categories are the Albini-Anderson fuel model type 3 (A-A M3), with $0.744 \mathrm{~kg} / \mathrm{m}^{2}$ [3], and the Scott-Burgan fuel model GR4 (S-B GR4), with a fuel load of $0.531 \mathrm{~kg} / \mathrm{m}^{2}$ [4]. In Sipnate canyon, the midflame wind direction was parallel to the main canyon axis and midflame speed was $1.8 \mathrm{~m} / \mathrm{s}-4 \mathrm{~m} / \mathrm{s}(6.4 \mathrm{~km} / \mathrm{h}-14.4 \mathrm{~km} / \mathrm{h})$. Fine Fuel Moisture Content (FFMC) was 12\% - 14\% and moisture in live grass fuel was 30\%. The Dead Fuel Moisture of Extinction (ME) was estimated to be $40 \%$ because the original ME values for A-A M3 (25\%) and S-B GR4 (15\%) fuel models were not appropriate. The same problem for Mediterranean vegetation was also noted by Yebra et al. [5], and his ME estimation for grass vegetation of $40 \%$ corresponds to our experiences. The average slope of Sipnate 
canyon's main axis is $14 \%$. Fire propagation parameters were calculated using the BehavePlus3 simulation program, and results for A-A M3 and S-B GR4 fuel models and FFMC $12 \%$ are given in fig. 3 . The burned area at the bottom of the canyon was about 10 ha, so the total released heat energy caused by vegetation burning could be estimated to be 550 GJ - 750 GJ. The Rothermel equations and the BehavePlus3 program suppose a constant rate of spread for the fire, and according to them, arrival time from the point visible from the accident to the location of the accident (distance $350 \mathrm{~m}$ ) is between $5.21 \mathrm{~min}$ to $15.91 \mathrm{~min}$, which is not realistic.

\section{S-B GR4}

\begin{tabular}{|c|c|c|c|c|c|c|}
\hline Midflame & Rate of & Heat per & Fireline & Flame & Reaction & Spread \\
\hline Wind Speed & Spread & Unit Area & Intensity & Length & Intensity & Distance \\
\hline $\mathrm{km} / \mathrm{h}$ & $\mathrm{m} / \mathrm{min}$ & $\mathrm{kJ} / \mathrm{m} 2$ & $\mathrm{~kW} / \mathrm{m}$ & $\mathrm{m}$ & $\mathrm{kW} / \mathrm{m} 2$ & $\mathrm{~m}$ \\
\hline 6.4 & 22.0 & 5123 & 1877 & 2.5 & 406 & 1319.2 \\
\hline 9.6 & 38.1 & 5123 & 3252 & 3.2 & 406 & 2285.4 \\
\hline 14.4 & 67.2 & 5123 & 5735 & 4.1 & 406 & 4030.1 \\
\hline
\end{tabular}

Figure 3: Fire propagation parameters in the canyon for Albini-Anderson type 3 and Scott-Burgan GR4 fuel categories.

The firefighters were quite experienced, so if the arrival time of the fire front in Sipnate canyon was 5 to 15 minutes, they would have had enough time to escape. Thus, our conclusion was that the Rothermel model was not appropriate for the calculation of the rate of spread of the fire in Sipnate canyon. Another possibility is the Viegas eruptive fire model, described in detail in a separate paper [6]. Here, we will only mention that an eruptive fire effect was possible in Sipnate canyon. In the case of eruptive fire behaviour, estimated time of arrival for the same distance of $350 \mathrm{~m}$ is between $60 \mathrm{~s}$ and $200 \mathrm{~s}$.

\section{Flow analysis in characteristic cross sections (2D)}

Due to a lack of adequate computer programs, the authors had to simplify the assumptions and perform the flow and thermal analyses that best fit the facts [1, 7]. Therefore, two 2D flows are analysed with the CFD package (ADINA). Fig. 4 shows (relative) vectors of flow prediction over the Veli Vrh hillside exposed to SE wind. In the first step, only the east wind component was considered. The next step was also a simplified 2D analysis of the flow through the canyon or the component from the southern direction, which gives an expected boundary layer development shown in fig. 5. Assumed resultant flow and fire line propagation are shown in fig. 6.

This flow is confirmed by another fact - the development of the boundary layer thickness 'written' on the leaves of several small trees along the canyon axis. At the origin of the canyon, dehydrated leaves (not burned) have heights of $0.5 \mathrm{~m}$ above the ground level. Leaves above this level were green. On another tree, approximately in the middle of the canyon, the height of dehydrated leaves was around $1.7 \mathrm{~m}$, and at the end it was almost $3 \mathrm{~m}$. The direction of the leaves follows the canyon axis direction, and thus validates the assumption of hot air flow. 


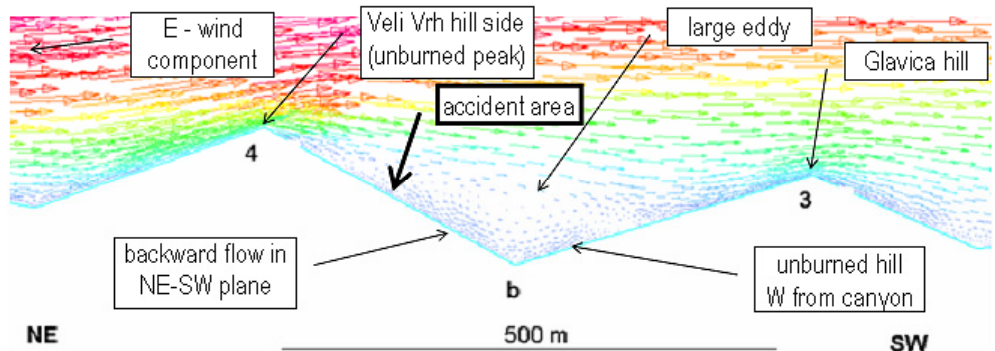

Figure 4: Unexpected backward flow (E component of S-E wind) due to a large eddy over Veli Vrh hill side over canyon.

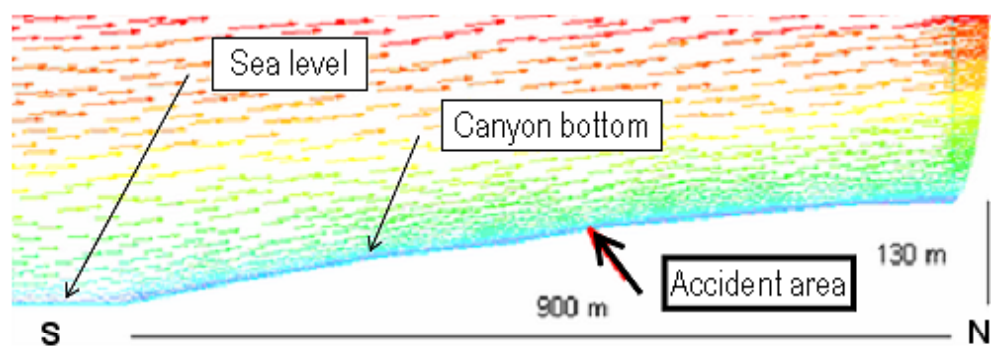

Figure 5: $\quad$ Expected axial flow (S component of S-E wind) through canyon axis and boundary layer formation.

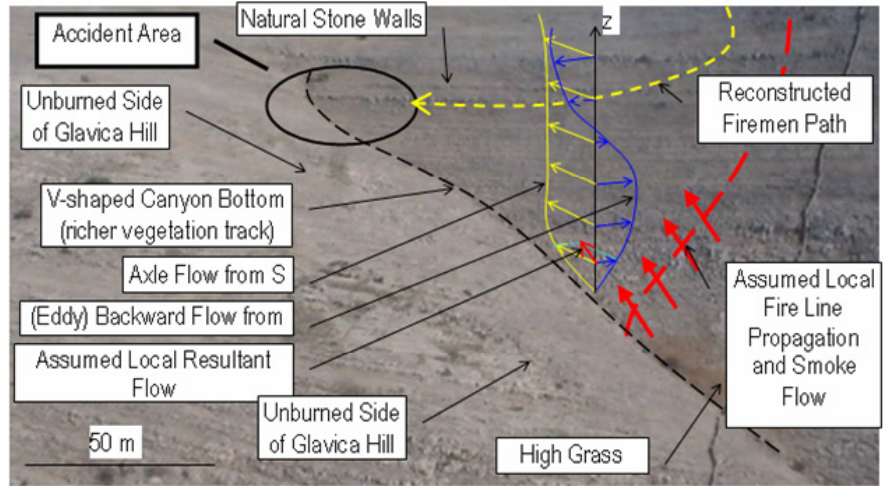

Figure 6: Assumed resultant flow on the right side of the canyon, with fire line propagation according to reconstruction.

\section{Thermal boundary layer and Fast Heat Shock phenomenon}

Thermodynamic analysis was based on the assumption that the downwind terrain section was quickly burned. However, a fast inflammation effect is not sufficient to explain the accident, particularly the firefighters' severe injuries. Therefore, 
after analysing all the evidence, Ninic and Nizetic derived one possible explanation, called the Fast Heat Shock (FHS) [1,8]. The situation just before the accident is illustrated in as an aerial view in fig. 1. and fig. 6. In the vertical plane through the firefighters position in the wind direction, the situation was as shown in fig. 7a). $\alpha$ indicates the fire front position before fast inflammation, $\alpha \beta$ is the quickly burned section, and $\gamma$ is the location of the firefighters. According to our theory, they may have been surrounded by the flames or in the enclosure of the rapidly shifted fire front $\beta$. In any case, at the moment of inflammation of section $\alpha \beta$, our modelling of the accident includes fast heat input along the $\alpha \beta$ section. This heat input caused temperature-turbulent boundary layer formation. Its thickness at location $\gamma$ was $2.5 \mathrm{~m}$, known as the height of the dehydrated leaves on small trees in the area. Because our mission was to estimate only the possibility of an accident due to natural causes, we assumed relatively unfavourable circumstances. Among other assumptions, this includes a relatively low air excess factor $\lambda=1.5$. Also, local air speed at $2.5 \mathrm{~m}$ above the ground was estimated to be $10 \mathrm{~m} / \mathrm{s}$, and dry grassy fuel was estimated to be $0.6 \mathrm{~kg} / \mathrm{m}^{2}$. With the assumed effective flame temperature and inflammated section length, this input data provided iterative estimation of the mean temperature in a boundary layer at accident location $\gamma$.

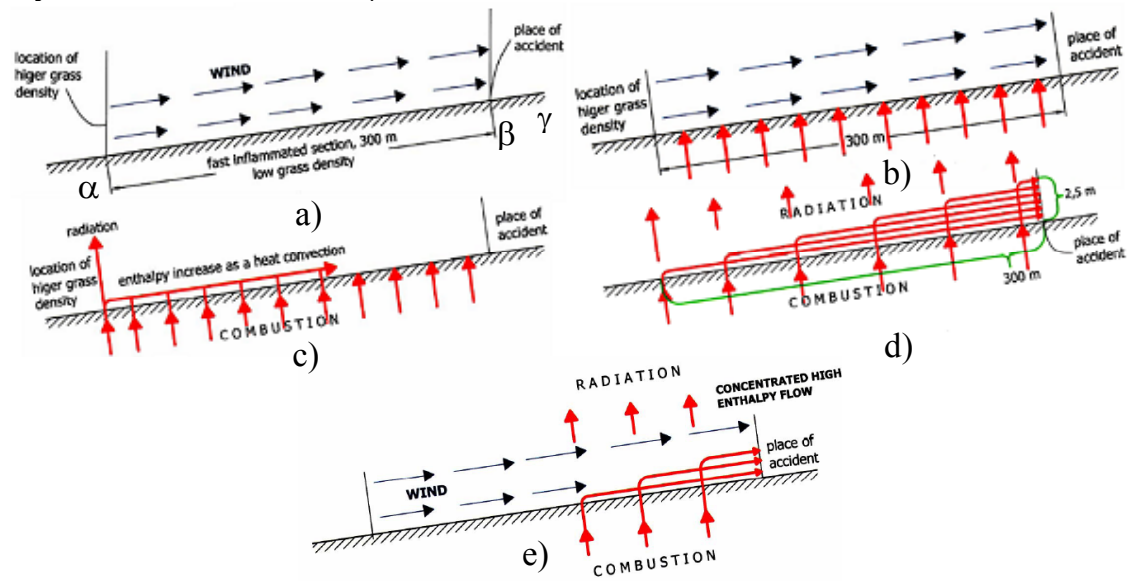

Figure 7: $\quad$ FTS development according to Ninic and Nizetic [8].

From the First Law of thermodynamics, energy balance for flow through a rectangular space of length $\alpha \beta$ and height $\delta=2.5 \mathrm{~m}$, we obtain:

$$
\left(m_{z}+G_{g}\right) \cdot c_{P} \cdot\left(T-T_{a}\right)=G_{g} \cdot H_{d}-E_{z r}
$$

where $m_{z}$ is the volume flow through the rectangular space, $G_{g}$ is fuel 'flow', $c_{p}$ is the specific thermal capacity factor of the combustion products, $T$ and $T_{a}$ are the temperatures of hot combustion products at accident locations $\gamma$ and on $\alpha$ (near surrounding air temperature), $H_{d}$ is the lower heat value of the dry grass and $E_{z r}$ is the heat flow by radiation into area. For our input data, the calculated hot wind 
temperature was $420 \mathrm{~K}\left(150^{\circ} \mathrm{C}\right)$ and the duration was 2-3 minutes. Results show that this mechanism, called 'FHS - fast heat shock', explains the unusually violent consequences from apparently harmless circumstances. This explanation is independent of the fast inflammation mechanism. The beginning, development to full scale and break-up of this phenomenon are shown on fig. 7a) - fig. 7e).

\section{Conclusions}

We conclude that the eruptive fire thesis alone could not explain the severe firefighter injuries and accident development, so we propose another approach, called FHS - Fast Heat Shock. According to the reconstruction, the helicopter with the firefighters landed at the north side of Sipnate canyon and the firefighters were on their way to the water reservoir previously left by the same helicopter on the south slope of Veli Vrh. The fire front was approaching from the south-east east direction following the main island axis, but the propagation on the north island side was faster, so the firefighters saw the fire front on the east side of the canyon first. The probably decided to retreat from the fire, so they turned west toward the canyon axis, as shown in fig. 8. According to our fire propagation simulation, it is possible that the fire also entered Sipnate canyon from the south part. This was not visible from where firefighters were at that moment.

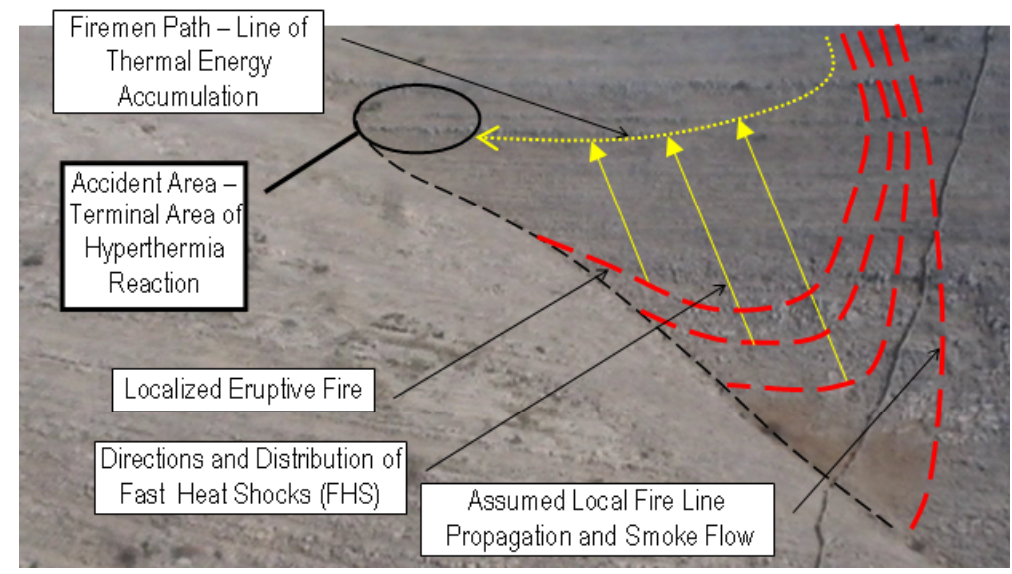

Figure 8: The possible accident scenario with FHS paths.

The fire front on the hill followed the wind direction, but in the canyon, global turbulence occurred and relative air flow was unexpectedly backward in a cross-sectional plane. Simultaneously, the surface flow followed the canyon axis as expected. The resultant wind speed would tend to be slightly opposite from the main wind direction. The moment the firefighter group reached the critical area, which is quite close to the canyon axis, it is possible that fire development in canyon had reached the eruptive point. The fire line entered the bottom of the 
canyon section, not visible from the firefighters' position. We suppose that first smoke and then hot air came to the location of the accident. The surprised group of firefighters reacted instinctively by trying to escape, discarding their equipment, which was found behind them. The firefighters were trapped between the fire front on the west and the fire from the canyon, so they had only one escape direction, northwest, and that was the reason why they were found at different places in the northwest direction. There are several facts that could be used for accident reconstruction - the direction of dehydrated leaves, the height of dry leaves or boundary layer thickness development, and unburned grass between stones and in terrain gaps, confirming very fast and turbulent hot air flow near the ground that could have caused additional thermal injuries to the firefighters. Simplified 2D flow analysis in characteristic planes gives relative values and a qualitative explanation of the problem. Analysis errors were not estimated because of the unknown terms of the real process, so we plan additional research based on more precise models for the fire spread in Sipnate canyon. In this paper, we propose FHS as one possible explanation for the Kornati accident caused only by natural forces. We think that the development of the FHS effect was very fast. The eruptive fire effect was the initial trigger of FHS, but its further development was probably caused by other effects described in this paper, primarily the existence of a lower jet stream from the southeast.

\section{References}

[1] Interdisciplinary working group, The Kornati Accident Report, Split, Zagreb, Croatia, 600 pages, Feb. 2008 (in Croatian)

[2] Stipanicev, D., Spanjol, Z., Vucetic, M., Vucetic, V., Rosavec, R., Bodrozic, Lj., The Kornati Fire Accident Facts and Figures - Configuration, Vegetation and Meteorology, Forest Fires 2008, Toledo (this conference)

[3] Anderson, H. E. Aids to determining fuel models for estimating fire behavior. USDA For. Serv. Gen. Tech. Rep. INT-122, 22p. 1982.

[4] Scott, J. H.; Burgan, R. E. Standard fire behavior fuel models: a comprehensive set for use with Rothermel's surface fire spread model, Gen. Tech. Rep. RMRS-GTR-153. U.S. Department of Agriculture, 72 p. 2005.

[5] Yebra, M., Aguardo, I., Garcia, M., Nieto, H., Chuvieco, E. et Salas, J. 2007. Fuel moisture estimation for fire ignition mapping, Wildfire 2007. Sevilla

[6] Viegas, D.X., Stipanicev, D., Ribeiro, L., Pita, L., Rossa, C., The Kornati Fire Accident - Eruptive Fire in Relatively Low Fuel Load Herbaceous Fuel Conditions ?, Forest Fires 2008, Toledo (this conference)

[7] Klarin, B.: Aerodynamic aspects of the Kornati accident - Workshop Forest Fire Behavior Research and Kornati Fire Accident - Facts and Preliminary Research Results, Feb. 4th 08, Split, http://laris.fesb.hr/Kornati-040208.htm

[8] Ninic, N., Nizetic, S.: Thermodynamic aspects of Kornati accident, Workshop Forest Fire Behavior Research and Kornati Fire Accident Facts and Preliminary Research Results, Feb. 4th 2008, Split, Croatia, http://laris.fesb.hr/Kornati-040208.htm 